\title{
1 Polycyclic Aromatic Hydrocarbons in ocean 2 sediments from the North Pacific to the Arctic Ocean
}

4 Yuxin Ma ${ }^{1}$, Crispin J. Halsall ${ }^{2,}{ }^{*}$, Zhiyong Xie ${ }^{3}$, Danijela Koetke ${ }^{3}$, Wenying Mi ${ }^{3}$, Ralf Ebinghaus ${ }^{3}$, Guoping Gao ${ }^{1, * *}$

$6{ }^{1}$ College of Marine Sciences, Shanghai Ocean University, Shanghai 201306, China

$7 \quad{ }^{2}$ Lancaster Environment Centre, Lancaster University, Lancaster, LA1 4YQ, UK

8 Department of Chemistry, Lancaster University, Lancaster, LA1 4YB, UK

$9{ }^{3}$ Helmholtz-Zentrum Geesthacht, Centre for Materials and Coastal Research GmbH,

10 Institute of Coastal Research, Max-Planck Straße. 1, D-21502 Geesthacht, Germany

11

$12 *$ Corresponding author. Tel.: +44-0-1524594330

13 E-mail: c.halsall@lancaster.ac.uk

$14 \quad * *$ Corresponding author. Tel.: +86-15692160123

15 E-mail: gpgao@shou.edu.cn 


\section{ABSTRACT}

Eighteen polycyclic aromatic hydrocarbons (PAHs) were measured in surficial sediments along a marine transect from the North Pacific into the Arctic Ocean. The highest average $\Sigma_{18} \mathrm{PAHs}$ concentrations were observed along the continental slope of the Canada Basin in the Arctic $\left(68.3 \pm 8.5 \mathrm{ng} \mathrm{g}^{-1} \mathrm{dw}\right)$, followed by sediments in the Chukchi Sea shelf $\left(49.7 \pm 21.2 \mathrm{ng} \mathrm{g}^{-1} \mathrm{dw}\right)$ and Bering Sea $\left(39.5 \pm 11.3 \mathrm{ng} \mathrm{g}^{-1} \mathrm{dw}\right)$, while the Bering Strait $\left(16.8 \pm 7.1 \mathrm{ng} \mathrm{g}^{-1} \mathrm{dw}\right)$ and Central Arctic Ocean sediments $\left(13.1 \pm 9.6 \mathrm{ng} \mathrm{g}^{-1} \mathrm{dw}\right)$ had relatively lower average concentrations. The use of principal components analysis with multiple linear regression (PCA/MLR) indicated that on average oil related or petrogenic sources contributed $\sim 42 \%$ of the measured PAHs in the sediments and marked by higher concentrations of two methylnaphthalenes over the non-alkylated parent PAH, naphthalene. Wood and coal combustion contributed $\sim 32 \%$, and high temperature pyrogenic sources contributing $\sim 26 \%$. Petrogenic sources, such as oil seeps, allochthonous coal and coastally eroded material such as terrigenous sediments particularly affected the Chukchi Sea shelf and slope of the Canada Basin, while biomass and coal combustion sources appeared to have greater influence in the central Arctic Ocean, possibly due to the effects of episodic summertime forest fires.

Keywords: polycyclic aromatic hydrocarbons, Arctic, sediment, source apportionment.

Capsule: PAH concentrations, composition and sources is relatively heterogenous in remote marine sediment from North Pacific to the central Arctic Ocean 


\section{INTRODUCTION}

Polycyclic aromatic hydrocarbons (PAHs) are carcinogenic and mutagenic pollutants originating from incomplete combustion and pyrolysis of carbonaceous materials (Ding et al., 2007; Okona-Mensah et al., 2005). They have both anthropogenic and natural sources. In particular, PAHs are well established markers with the ability to trace specific sources of anthropogenic contamination (i.e. fossil fuel vs. biomass combustion) and natural inputs (i.e. oil seeps, forest fires and terrestrial debris) to marine systems (Jaward et al., 2004; Nizzetto et al., 2008; Yunker et al., 2002a; Yunker et al., 2002b). Although PAHs represent only a small fraction (0.2-7\%) of the total composition of crude oil, their relative persistence in the environment and potential toxicity to marine organisms warrants research into their sources and fate in marine systems (Harvey et al., 2014).

Analysis of benthic marine sediments allows the assessment of particle settling and post-depositional behavior as an important marine sink for contaminants initially present in the overlying water column (Ma et al., 2015; Yunker et al., 1996). For PAHs that possess relatively high organic-carbon/water partitioning coefficients (e.g. $\log \mathrm{K}_{\mathrm{OC}} \geq 4.5$ ) then their sorption to organic matter (Dachs and Eisenreich, 2000) and subsequent particle settling could be a significant removal process from the water column. Part of the particle settling could be driven by the 'biological pump', which is the settling flux of particle organic carbon associated with primary production by phytoplankton (Dachs et al., 2002; Galban-Malagon et al., 2012). Marine snow also contributes significantly to the PAHs deposition in the seafloor, especially in the 
Arctic environment (Daly et al., 2016; Passow et al., 2012). However, the process of re-mineralization during settling and diagenesis after deposition might further influence the vertical removal, settling rates and residence times of PAHs in water column and sediment (Adhikari et al., 2015; Adhikari et al., 2016).

For remote pelagic environments like the North Pacific and Arctic Oceans, then PAH input is likely to be driven primarily by atmospheric deposition (MacDonald et al., 2000). As PAHs have been systematically monitored in ambient Arctic air at sites in Canada and the Norwegian Arctic (Becker et al., 2006; Wang et al., 2010), continental sources of PAHs via long-range transport from mid-latitudes have been demonstrated by several modeling studies (Halsall et al., 1997; Hung et al., 2005; Sofowote et al., 2011; Wang et al., 2010). The observed air-sea gas exchange gradients of PAHs from the North Pacific to the Arctic Ocean, strongly favored net deposition, with increasing deposition with increasing latitude (Ma et al., 2013). However, in addition to atmospheric sources and subsequent deposition to marine surfaces, the extraction and processing of fossil fuels on the wide Arctic shelf seas and adjacent coastal areas provides a petrogenic source of PAHs to sediments (Yunker et al., 2002a; Yunker and Macdonald, 1995; Yunker et al., 2011). Climate change perturbations are also driving increased coastal erosion and permafrost thawing in the Arctic (AMAP, 2012). This increases the likelihood of the wider dispersal of petrogenic PAHs (McGuire et al., 2009), such as transport over long distances via turbidity currents, as well as the offshore transport of sediment-laden ice from the coastal shelf areas and subsequent export between the shelves and the central Arctic Ocean (Belicka and Harvey, 2009). 
The aim of this study was to examine the spatial distribution of PAHs in benthic sediments from the North Pacific to the central Arctic Ocean (via the Bering Strait) to infer the relevance of different PAH sources by examining their composition using PAH ratios and statistical pattern recognition techniques. The study of the sedimentary PAH profile can be related to sources and/or processing of these chemicals to and within the marine system and this approach should be able to put long-range transport and atmospheric sources into context with other petrogenic/sedimentary sources.

\section{MATERIALS and METHODS}

\section{Sampling}

During the $4^{\text {th }}$ Chinese National Arctic Research Expedition held between July and September 2010 (CHINARE 4), 0-2cm surficial marine sediment samples were collected onboard the ice-breaker R/V Xuelong ('Snow Dragon’). The sampling cruise generally covered a northward transect from the Bering Sea, through the Bering Strait to the Chukchi Sea, and across the Canada Basin and central Arctic Ocean $\left(53-88^{\circ} \mathrm{N}\right)$. Detailed information about the sampling work and the sediment samples are described in Supplementary Materials and listed in Table S1.

Extraction, Analysis, $Q C / Q A$

Extraction, fractionation and analysis of the samples was based on our previously published method (Zhong et al., 2012), and is described in more detail in the Supplementary Materials. Eighteen PAH compounds were analysed in this research, including 16 parent-PAHs and 2 alkylated-PAHs: naphthalene (Nap), 
1-methylnaphthalene (1-MN), 2-methylnaphthalene (2-MN), acenaphthylene (Acl), acenaphthene (Ace), fluorene (Flu), phenanthrene (Phe), anthracene (Ant), fluoranthene (Fluor), pyrene (Py), benzo[a]anthracene (BaA), chrysene (Chry), benzo[b]fluoranthene $(\mathrm{BbF})$, benzo[k]fluoranthene $(\mathrm{BkF})$, benzo[a]pyrene $(\mathrm{BaP})$, indeno[1,2,3-cd]pyrene (InP), dibenz[a,h]anthracene (DBahA), benzo[ghi]perylene (BghiP). A PAH-Mix containing 9 deuterated compounds (see Table S2) were added as surrogate standards to monitor matrix effects with ${ }^{13} \mathrm{C}-\mathrm{PCB} 208$ added as an injection standard. The recoveries of target PAHs ranged from $60 \pm 3 \%$ to $91 \pm 7 \%$ in 5 spiked samples. In total five procedural blanks were extracted together with the samples. The method detection limits (MDLs) for each PAH were derived from the procedural blanks and quantified as the mean field blank plus three times the standard deviation $(3 \sigma)$ of the field blanks. MDLs ranged from $0.001 \mathrm{ng} / \mathrm{g}$ for $\mathrm{BkF}$ to 0.053 ng/g for Nap. The major PAH contamination found in the procedural blanks comprised of Nap, Phe and Py with concentrations of $0.028 \pm 0.008,0.019 \pm 0.007$ and $0.017 \pm 0.007 \mathrm{ng} / \mathrm{g}$, which account for $<1.1 \%$ of those compounds in the sediment samples.

\section{RESULTS and DISCUSSION}

\section{Geographic Distribution of PAHs}

The total concentrations of $18 \mathrm{PAHs}$ in the surface sediment $\left(\Sigma_{18} \mathrm{PAHs}\right.$, sum of the detected 16 parent PAHs and 2 alkyl-PAHs) ranged from 8.5 to $78.3 \mathrm{ng} \mathrm{g}^{-1}$ dry weight (dw), with a mean of $37.3 \pm 24.0 \mathrm{ng} \mathrm{g}^{-1} \mathrm{dw}$ over the entire cruise track. The sampling 
stations were separated into five geographical areas as: Bering Sea, Bering Strait, Chukchi Sea, Canadian Basin margin and Central Arctic Ocean to assess the spatial distribution of the PAHs. A summary of the chemical concentrations in these areas is presented in Table 1 and the spatial distribution of $\Sigma_{18}$ PAHs along the cruise track is shown in Figure 1. Analysis of variance (ANOVA) demonstrated significant differences in the mean concentrations between the five geographical regions.

The highest average $\Sigma_{18} \mathrm{PAHs}$ concentrations were observed in the Canada Basin margin region $\left(68.3 \pm 8.5 \mathrm{ng} \mathrm{g}^{-1} \mathrm{dw}\right)$, followed by sample stations in the Chukchi Sea (49.7 $\left.\pm 21.2 \mathrm{ng} \mathrm{g}^{-1} \mathrm{dw}\right)$ and Bering Sea $\left(39.5 \pm 11.3 \mathrm{ng} \mathrm{g}^{-1} \mathrm{dw}\right)$, while the Bering Strait $\left(16.8 \pm 7.1 \mathrm{ng} \mathrm{g}^{-1} \mathrm{dw}\right)$ and Central Arctic Ocean $\left(13.1 \pm 9.6 \mathrm{ng} \mathrm{g}^{-1} \mathrm{dw}\right)$ had relatively lower average concentrations. It is noteworthy that concentrations of $\Sigma_{18}$ PAHs showed a wide variability in the Chukchi Sea with high levels observed in sediments at sites SR11 (78.3 $\left.\mathrm{ng} \mathrm{g}^{-1} \mathrm{dw}\right)$ and $\mathrm{C} 07\left(75.8 \mathrm{ng} \mathrm{g}^{-1} \mathrm{dw}\right)$ in the northern Chukchi Sea shelf, as well as site BN03 in the Chukchi Sea marine bench edge (71.8 $\mathrm{ng} \mathrm{g}^{-1} \mathrm{dw}$ ). Relatively lower concentrations were observed at sites SR01 (8.8 $\mathrm{ng} \mathrm{g}^{-1}$ $\mathrm{dw})$ and SR04 (27.7 $\left.\mathrm{ng} \mathrm{g}^{-1} \mathrm{dw}\right)$ in the southern Chukchi Sea shelf and site M02 (28.6 ng $\mathrm{g}^{-1} \mathrm{dw}$ ) in the Chukchi Sea basin. However, in the margin edges of the Canada Basin, high $\Sigma_{18}$ PAHs levels were observed at sites S26 (75.5 $\left.\mathrm{ng} \mathrm{g}^{-1} \mathrm{dw}\right)$ and MS02 (70.5 $\mathrm{ng} \mathrm{g}^{-1} \mathrm{dw}$ ), respectively. Compared with legacy POPs in surficial sediment of the same region, some differences exist for their spatial distribution patterns. OCs and PCBs all had significantly higher concentrations in the relatively shallow water of the Bering-Chukchi shelf areas compared to the deeper water regions of the Bering Sea 
and Arctic Ocean. Lower PAHs levels in the surface sediment of Bering Strait might be due to particle mediated biodegradation processes. But for continental shelf margins of the Chukchi Sea and Canada Basin, some additional petrogenic sources other than atmospheric sources might also contribute to the PAHs observed in benthic sediments and this is discussed in detail below.

Compared with the distribution of PAHs in the atmosphere and surface seawater in the same regions (which were also observed in the same cruise (see Ma et al., 2013)), the PAH occurrence in the sediment was quite different. Generally, the atmospheric PAHs over the Arctic Ocean displayed higher concentrations than those observed over the North Pacific Ocean and this was attributed to 'within Arctic' sources at the time of the cruise (Arctic summer), while a decreasing trend in concentrations in surface seawater was observed with increasing latitude. This was possibly due to more effective biogeochemical removal processes in the water column (Ma et al., 2013). Although the observed air-sea gas exchange gradients strongly favored net deposition of PAHs, their efficient removal from surface waters and the water column via particle mediated biodegradation may reduce efficient transfer of these chemicals to deep water environments and benthic sediments (Berrojalbiz et al., 2011; Lohmann et al., 2009; Yunker et al., 2002a). The remineralization of particulate organic carbon along the vertical transport gradients results in the release and recycling of sorbed PAHs, and cycling of PAHs in the sediments (Adhikari et al., 2015). Sediment mixing can result to such distinct distribution of PAHs between seawater and sediments (Adhikari et al., 2016; Tarr et al., 2016). In addition to atmospheric sources, petrogenic sources 
171 such as oil seeps and export of PAH-laden sediments from coastal regions to the shelf 172 margins might also contribute to the PAHs observed in benthic sediments, particularly 173 in the continental shelf margins of the Chukchi Sea and Canada Basin and this is 174 discussed further below.

175 Compare with PAHs in other Arctic surrounding sea regions, the present results for 176 the Chukchi Sea and edge of Canada Basin sediments are comparable to PAHs 177 observed in Kara Sea (not detected $-110 \mathrm{ng} \mathrm{g}^{-1}$ ) and Svalbard coast (25-38 ng g $\mathrm{g}^{-1}$ ), but 178 lower than those in Barents Sea (18-500 ng g ${ }^{-1}$ ) and Beaufort Sea Shelf (290-1200 ng $179 \mathrm{~g}^{-1}$ ) (Jiao et al., 2009; Sericano et al., 2001; Yunker et al., 1996). For sediments 180 obtained from the central Arctic Ocean, our results are also comparable to 181 concentrations obtained in the Makarov Basin, but about 10-fold lower than those 182 observed in the Amundsen and Nansen Basins (Yunker et al., 2011). While in 183 comparison with other ocean area, our results are significantly lower than PAHs 184 observed in North Sea (700-2700 ng g ${ }^{-1}$ ) and Baltic Sea (9.53-1870 ng g ${ }^{-1}$ ) (Klamer 185 and Fomsgaard, 1993; Witt, 1995).

186 The TOC level in these surficial sediments (see Table S1) was higher in the shelf 187 regions of the Bering Strait (average value of $0.64 \%$ ) and Chukchi Sea (average value 188 of $0.60 \%$ ), and decreased towards the Bering Sea (average value of $0.43 \%$ ), Canada 189 Basin margins (average value of $0.27 \%$ ), and the central Arctic Ocean (average value 190 of $0.10 \%$ ). Moreover, correlations were not so strong between $\Sigma_{18} \mathrm{PAHs}$ and TOC for 191 the entire cruise $\left(r^{2}=0.367, p<0.05, n=30\right)$. No significant correlations have been 192 observed between PAHs and TOC in other Arctic regions reported before (Yunker et 
193

194

195

al., 2011). For persistent organic pollutants (POPs), such as PCBs, weak or insignificant relationships were obtained between TOC and these chemicals (Ma et al., 2015). Since the sedimentation rates varied across the study transect, the surficial sediment samples collected here (collected to a depth of $\sim 2 \mathrm{~cm}$ ) represent sediment that has accumulated over greatly differing time periods. Sedimentation rates along the edge of the continental shelf of the Chukchi Sea with the Canada Basin (i.e., the Chukchi-Alaskan margin) ranged from 0.4 to $12 \mathrm{~m} / \mathrm{kyr}$ with average rates of between 1.50 and $3.13 \mathrm{~m} / \mathrm{kyr}$, while the sedimentation rates were estimated only to be 0.01-0.02 $\mathrm{m} / \mathrm{kyr}$ in the central Arctic Ocean. Thus for the higher sedimentation rate regions such as the northern Bering and Chukchi Seas, the sediments comprise of material that has accumulated over the last few decades. While for the material collected in the lower accumulation regions (e.g. Canada Basin and central Arctic Ocean) the sediments represent accumulation over 100s of years and hence represent time periods when PAH sources and input to the deep ocean environment may have changed considerably (Darby et al., 2009). Additionally, although some PAHs may reach the deep water environment associated with organic matter, water-column and sediment layer processing such as biodegradation and re-partitioning of PAHs to mineral matter, may account for the weak relationship observed between TOC and chemicals like PAHs present in remote marine oceans.

\section{PAH Composition}

Generally, the lighter PAHs such as Nap, its alkylated derivatives (1-MN and 2-MN), 
and Phe, with average concentrations ranging 4-6 $\mathrm{ng} \mathrm{g}^{-1} \mathrm{dw}$, were the most abundant PAHs in the sediments along the cruise track, and contributed $>50 \%$ to $\Sigma_{18} \mathrm{PAHs}$. The higher MW PAHs such as Chry, BbF and BghiP, had lower concentrations of 2-3 ng $\mathrm{g}^{-1} \mathrm{dw}$. Levels of other detected PAHs were lower, with average concentrations $\leq 1 \mathrm{ng}$ $\mathrm{g}^{-1} \mathrm{dw}$. Moreover, although only two alkyl-PAHs were measured in this study (1-MN and 2-MN), they were more abundant than their parent PAH (Nap) at all locations along the cruise (Figure 2). Previous studies indicate that the alkyl-substituted PAHs in sediment are likely derived from petrogenic inputs and this dominance of alkyl-PAHs has been previously reported in sediments collected from the northeastern Chukchi and Beaufort Sea shelves (Harvey et al., 2014; Yunker et al., 1996). Although it varies with sampling location, Adhikari et al., 2015, 2016 have reported that the alkylated PAHs contribute to the major vertical fluxes and also contribute significantly to the PAHs distribution in the northern Gulf of Mexico sediments even in natural background conditions (Adhikari et al., 2015; Adhikari et al., 2016).

The PAH profile observed in surface seawater and boundary-layer air over the same oceanic transect was dominated by the lower MW PAHs, with 2-MN, Phe and Py contributing about $50 \%$ to the dissolved $\Sigma_{18}[\mathrm{PAHs}]_{\mathrm{wat}}$ in the seawater. However, concentrations of atmospheric heavier 5-6 ringed PAHs, which were mainly detected in the particulate phase, were quite low, while their levels were extremely low in surface seawater (Ma et al., 2013). Therefore, similarities in the PAH profile between the atmosphere, surface seawater and benthic sediments are apparent for the low MW PAHs only, although it is difficult to ascertain the influence of atmospheric sources on 
the PAHs present in benthic sediments, especially given water column 'processing' prior to and during particle settling (Harvey et al., 2014).

\section{Source Identification by MDR}

Two different molecular diagnostic ratios (MDR) were calculated to estimate the influence of potential sources for the PAHs present in the sediment. The ratios of Fluor/(Fluor + Py) and $\mathrm{InP} /($ BghiP $+\mathrm{InP})$ in the surface sediment along the cruise tracks ranged from 0.26 to 0.57 and from 0.14 to 0.61 , respectively, suggesting a well-mixed source profile of petrogenic, petrogenic-combustion, as well as biomass and coal combustion origin (Figure 3-a). Similarly, a well-mixed source profile was also demonstrated for surface seawater from the North Pacific to the Arctic Ocean by MDR, however, MDR applied to the boundary-layer air of the same region indicated combustion of biomass or coal only as the principle sources of PAHs (Ma et al., 2013). MDRs however should be interpreted with some caution due to different environmental processing of the isomers during atmospheric transport and water column vertical transport such as biodegradation, photo-oxidation (Galarneau, 2008). MDRs calculated here provide a relative assessment between the various marine compartments. They demonstrate that part of the PAH component in the sediments, surface seawater and atmosphere share the same source profile, which to some extent might be due to air-sea gas exchange and subsequent transfer through the water column, although differences in the MDR indicate a degree of 'uncoupling' between these compartments.. 
Specifically, in the sediments of Bering Sea, the ratios of Fluor/(Fluor + Py) and $\mathrm{InP} /(\mathrm{BghiP}+\mathrm{InP})$ were $<0.4$ and 0.2 respectively, indicating a petrogenic source (Figure 3-b). While for the Chukchi Sea shelf and slope of the Canadian Basin region, Fluor/(Fluor + Py) and InP/(BghiP + InP) were higher and ranged from 0.39-0.48 and 0.19-0.34 respectively, indicating mixing sources of petrogenic-derived and petroleum combustion-derived PAHs (Figure 3-c). The dominance of the two alkyl PAHs (1-MN and 2-MN) also support the petrogenic influence on the PAHs observed in these sediments (Figure 2). The Chukchi Sea, for example, is estimated to contain 15 billion barrels of recoverable oil, with potential for this region to serve as a significant source of oil and natural gas in the future given that drilling rights have now been permitted (Harvey et al., 2014). PAH petrogenic markers might originate in oil from naturally occurring seeps on the Chukchi shelf, although this petrogenic signal might be localized and not extend to sediments in the continental shelf regions of the Canada Basin or central Arctic Ocean (Gautier et al., 2009). In addition, coastal terrestrially-derived PAHs might contribute to the sedimentary PAH profile in the Chukchi Sea shelf region and margins of the continental shelf. The organic-rich peat, shales, bitumens and coals that cover Alaska's North Slope tundra provide likely sources of alkyl-PAHs, with transport of particle matter over long distances via turbidity currents or ice rafting of sediments (Jones and Yu, 2010). Similarly, the Mackenzie River might supply elevated concentrations of alkyl-PAHs through the delivery of eroded bitumen from the watershed to the Canadian shelf (Yunker et al., 2002b; Yunker et al., 1996), a process that could be exacerbated by climate change in 
281

282

the Arctic (McGuire et al., 2009).

For several sample sites in the central Arctic Ocean, it is noteworthy that observed ratios of Fluor/(Fluor $+\mathrm{Py})$ and $\mathrm{InP} /(\mathrm{BghiP}+\mathrm{InP})$ indicate biomass combustion sources (Figure 3-d). Moreover, the contribution of parent PAH relative to alkyl-PAHs (ratio of $\mathrm{Nap} /(1-\mathrm{MN}+2-\mathrm{MN})$ ) increased significantly in the central Arctic Ocean (Figure 2). To some extent, this suggests increasing import of parent PAHs on sedimentary PAHs in the central Arctic Ocean. Combustion PAH emissions from forest and prairie fires are dominated by parent PAHs which are transported atmospherically, as well as by the movement of sea and river ice with ice-associated particulate matter (Gelinas et al., 2001; Schmidt and Noack, 2000; Yunker et al., 2002b). During the CHINARE 2010 cruise, a clear increase of atmospheric PAHs, especially particle-bound PAHs, was observed in the central Arctic Ocean region, and attributed to forest fires in sub-Arctic regions of Alaska, Canada, Russia and Siberia during summer (Ma et al., 2013). From our results, these episodic inputs of pyrogenic PAHs appear to contribute to the PAHs present in the deep ocean sediments of the central Arctic Ocean, although significant PAH 'weathering' is likely to occur between the marine/atmosphere interface and the deep ocean sediments. The use of $\mathrm{PAH}$ ratios as source markers is limited once environmental weathering processes (chemical and biological) preferentially degrade/remove one PAH relative to another (Galarneau, 2008).

Source Apportionment Pattern Recognition and Multiple Linear Regression 
In order to have a quantitative understanding of the contributions of different PAH sources, principal component analysis (PCA) followed by multiple linear regression (MLR) of the data was used as the source apportionment method. Specifically, PCA allowed us to represent the total variability of the original PAH data in a minimum number of factors and the following MLR is used to determine the percent contribution of different PAH sources to the sediments of the entire cruise. The detailed procedure of PCA/MLR analysis was followed as previously reported by Larsen and Baker (2003) and is described in more detail in the Supplementary Materials. For the PCA results, three significant factors were determined which explained $88 \%$ of the total variability of the original PAH dataset (Table 2). The first factor was responsible for $32 \%$ of the total variance with a profile of Fluor, Py, Flu, $\mathrm{BaP}$ and $\mathrm{BaA}$, which indicated wood and coal combustion. It is reported that some of the lower MW PAHs like Fluor, Py and Flu are predominantly indicative of low to medium temperature combustion (i.e. inefficient combustion processes) associated with biomass combustion such as wood, but also coal combustion (Harrison et al., 1996; Simcik et al., 1999). The second factor was responsible for $29 \%$ of the total variance. This factor was predominately composed of Nap, 1-MN, 2-MN, Ace and Phe. These low MW PAHs in addition to the presence of alkyl-PAHs indicate that this factor was mainly dependent on oil related sources (Larsen and Baker, 2003; Yunker et al., 1996). The third factor accounted for $27 \%$ of the total variance and was predominately weighted by the higher MW PAHs such as IP, DBahA, BghiP BbF and BkF. These 5-6 ringed PAHs are mainly attributed to high temperature pyrogenic 
sources such as liquid fossil fuel combustion (Larsen and Baker, 2003; Venkataraman et al., 1994). Moreover, results of the following MLR showed that the mean percent contribution is $42.3 \%$ for the oil related sources, $32.1 \%$ for the wood and coal combustion sources, and $24 \%$ for the high temperature pyrogenic sources. It is noteworthy that the oil-related sources contributed to nearly half of the PAHs in the surficial sediments collected along the cruise transect, demonstrating that natural/petrogenic sources were important for the PAHs present in these remote ocean sediments, and indicating a degree of 'uncoupling' between the broad combustion-derived PAHs in the atmosphere and those present in benthic sediments.

\section{Conclusions}

This study provides insight into the PAH concentrations and composition in remote marine sediments in a transect that is relatively heterogenous with regards to the varied depth that the sediments were collected from i.e. shallow continental-shelf seas $v s$. deep ocean environments, and the rate of sedimentation. The evidence supporting the role played by petrogenic sources is based on examining only 18 PAHs and a more extensive set of analytes including alkanes, tricyclic terpanes, steranes and hopanes as biomarkers would be useful alongside a wider set of alkylated-PAHs to help distinguish specific source categories such as weathered oil, coal and eroded terrigenous material. Nonetheless, in comparison to our earlier study that examined the same PAHs in air and surface seawater along broadly the same transect (Ma et al., 2013), there are notable differences in the PAH profile between these 'surface' 
compartments and the sediments measured here. Notably the ratios of Fluo/Pyr and InP/BghiP are markedly lower in the sediments of the Chukchi Sea shelf and continental slope of the Canada Basin compared to air and surface water, supporting the petrogenic nature of the PAHs in these sediments. Furthermore, our findings show that the PAHs in the sediments of the central Arctic Ocean are dominated by non-fossil fuel combustion sources and is supported by the study of Yunker et al. (2011) who noted that the ubiquitous occurrence of allochthonous coal in surficial sediments made source attribution from other petrogenic sources (and probably other sources as well) difficult to determine. We recommend that for future campaigns driven by the need to understand contemporary pollution sources to air and surface waters - then a much broader set of geochemical organic analytes be screened for in collected sediment samples, and that chemical profiles be benchmarked against the chemical profiles observed in sediments that are dominated by petrogenic sources.

\section{ACKNOWLEDGEMENT}

We wish to express our sincere gratitude to all the members of the $4^{\text {th }}$ Chinese National Arctic Research Expedition. The research is supported by Youth Fund of National Natural Science Foundation of China (41506215) and Shanghai Sailing Program (15YF1405100). We acknowledge support from the UK NERC grant NE/E00511X/1 'ArcPOP' and EU FP7 project 'ArcRisk' (Contract no. 226534). The samples were supported by the Polar Sediment Sample Chamber of China. The sample analysis was carried out at Helmholtz-Zentrum Geesthacht, Centre for 
Research Program of China (2015CB953900). Entire datasets from this campaign are available from the corresponding authors or the first author, YM (xinxin0709@126.com).

\section{REFERENCES}

Adhikari, P.L., Maiti, K., Overton, E.B., 2015. Vertical fluxes of polycyclic aromatic hydrocarbons in the northern Gulf of Mexico. Marine Chemistry 168, 60-68.

Adhikari, P.L., Maiti, K., Overton, E.B., Rosenheim, B.E., Marx, B.D., 2016. Distributions and accumulation rates of polycyclic aromatic hydrocarbons in the northern Gulf of Mexico sediments. Environmental Pollution 212, 413-423.

AMAP, 2012. Arctic Climate Issues 2011: Changes in Arctic Snow, Water, Ice and Permafrost. SWIPA Overview Report., in: (AMAP), A.M.a.A.P. (Ed.), Oslo, p. xi + 97pp.

Becker, S., Halsall, C.J., Tych, W., Hung, H., Attewell, S., Blanchard, P., Li, H., Fellin, P., Stern, G., Billeck, B., Friesen, S., 2006. Resolving the long-term trends of polycyclic aromatic hydrocarbons in the Canadian Arctic atmosphere. Environmental Science \& Technology 40, 3217-3222.

Belicka, L.L., Harvey, H.R., 2009. The sequestration of terrestrial organic carbon in Arctic Ocean sediments: A comparison of methods and implications for regional carbon budgets. Geochimica Et Cosmochimica Acta 73, 6231-6248.

Berrojalbiz, N., Dachs, J., Ojeda, M.J., Valle, M.C., Castro-Jimenez, J., Wollgast, J., Ghiani, M., Hanke, G., Zaldivar, J.M., 2011. Biogeochemical and physical controls on concentrations of polycyclic aromatic hydrocarbons in water and plankton of the Mediterranean and Black Seas. Global Biogeochemical Cycles 25.

Dachs, J., Eisenreich, S.J., 2000. Adsorption onto aerosol soot carbon dominates gas-particle partitioning of polycyclic aromatic hydrocarbons. Environmental Science \& Technology 34, 3690-3697. Dachs, J., Lohmann, R., Ockenden, W.A., Mejanelle, L., Eisenreich, S.J., Jones, K.C., 2002. Oceanic biogeochemical controls on global dynamics of persistent organic pollutants. Environmental Science \& Technology 36, 4229-4237.

Daly, K.L., Passow, U., Chanton, J., Hollande, D., 2016. Assessing the impacts of oil-associated marine snow formation and sedimentation during and after the Deepwater Horizon oil spill. Anthropocene 13, 18-33.

Darby, D.A., Ortiz, J., Polyak, L., Lund, S., Jakobsson, M., Woodgate, R.A., 2009. The role of currents and sea ice in both slowly deposited central Arctic and rapidly deposited Chukchi-Alaskan margin sediments. Global and Planetary Change 68, 56-70.

Ding, X., Wang, X.M., Xie, Z.Q., Xiang, C.H., Mai, B.X., Sun, L.G., Zheng, M., Sheng, G.Y., Fu, J.M., Poschl, U., 2007. Atmospheric polycyclic aromatic hydrocarbons observed over the North Pacific Ocean and 
the Arctic area: Spatial distribution and source identification. Atmospheric Environment 41, 2061-2072.

Galarneau, E., 2008. Source specificity and atmospheric processing of airborne PAHs: Implications for source apportionment. Atmospheric Environment 42, 8139-8149.

Galban-Malagon, C., Berrojalbiz, N., Ojeda, M.J., Dachs, J., 2012. The oceanic biological pump modulates the atmospheric transport of persistent organic pollutants to the Arctic. Nature Communications 3.

Gautier, D.L., Bird, K.J., Charpentier, R.R., Grantz, A., Houseknecht, D.W., Klett, T.R., Moore, T.E., Pitman, J.K., Schenk, C.J., Schuenemeyer, J.H., Sorensen, K., Tennyson, M.E., Valin, Z.C., Wandrey, C.J., 2009. Assessment of Undiscovered Oil and Gas in the Arctic. Science 324, 1175-1179.

Gelinas, Y., Prentice, K.M., Baldock, J.A., Hedges, J.I., 2001. An improved thermal oxidation method for the quantification of soot/graphitic black carbon in sediments and soils. Environmental Science \& Technology 35, 3519-3525.

Halsall, C.J., Barrie, L.A., Fellin, P., Muir, D.C.G., Billeck, B.N., Lockhart, L., Rovinsky, F.Y., Kononov, E.Y., Pastukhov, B., 1997. Spatial and temporal variation of polycyclic aromatic hydrocarbons in the Arctic atmosphere. Environmental Science \& Technology 31, 3593-3599.

Harrison, R.M., Smith, D.J.T., Luhana, L., 1996. Source apportionment of atmospheric polycyclic aromatic hydrocarbons collected from an urban location in Birmingham, UK. Environmental Science \& Technology 30, 825-832.

Harvey, H.R., Taylor, K.A., Pie, H.V., Mitchelmore, C.L., 2014. Polycyclic aromatic and aliphatic hydrocarbons in Chukchi Sea biota and sediments and their toxicological response in the Arctic cod, Boreogadus saida. Deep-Sea Research Part li-Topical Studies in Oceanography 102, 32-55.

Hung, H., Blanchard, P., Halsall, C.J., Bidleman, T.F., Stern, G.A., Fellin, P., Muir, D.C.G., Barrie, L.A., Jantunen, L.M., Helm, P.A., Ma, J., Konoplev, A., 2005. Temporal and spatial variabilities of atmospheric polychlorinated biphenyls (PCBs), organochlorine $(\mathrm{OC})$ pesticides and polycyclic aromatic hydrocarbons (PAHs) in the Canadian Arctic: Results from a decade of monitoring. Science of the Total Environment 342, 119-144.

Jaward, F.M., Barber, J.L., Booij, K., Jones, K.C., 2004. Spatial distribution of atmospheric PAHs and PCNs along a north-south Atlantic transect. Environmental Pollution 132, 173-181. Jiao, L.P., Zheng, G.J., Minh, T.B., Richardson, B., Chen, L.Q., Zhang, Y.H., Yeung, L.W., Lam, J.C.W., Yang, X.L., Lam, P.K.S., Wong, M.H., 2009. Persistent toxic substances in remote lake and coastal sediments from Svalbard, Norwegian Arctic: Levels, sources and fluxes. Environmental Pollution 157, 1342-1351. Jones, M.C., Yu, Z., 2010. Rapid deglacial and early Holocene expansion of peatlands in Alaska. Proc.Natl.Acad.Sci. 107, 7347-7352.

Klamer, H.J.C., Fomsgaard, L., 1993. GEOGRAPHICAL-DISTRIBUTION OF CHLORINATED BIPHENYLS (CBS) AND POLYCYCLIC AROMATIC-HYDROCARBONS (PAHS) IN SURFACE SEDIMENTS FROM THE HUMBER PLUME, NORTH-SEA. Marine Pollution Bulletin 26, 201-206.

Larsen, R.K., Baker, J.E., 2003. Source Apportionment of Polycyclic Aromatic Hydrocarbons in the Urban Atmosphere: A Comparison of Three Methods. Environ. Sci. Technol 37, 1873-1881.

Lohmann, R., Gioia, R., Jones, K.C., Nizzetto, L., Temme, C., Xie, Z., Schulz-Bull, D., Hand, I., Morgan, E., Jantunen, L., 2009. Organochlorine Pesticides and PAHs in the Surface Water and Atmosphere of the North Atlantic and Arctic Ocean. Environmental Science \& Technology 43, 5633-5639.

Ma, Y.X., Halsall, C.J., Crosse, J.D., Graf, C., Cai, M.H., He, J.F., Gao, G.P., Jones, K., 2015. Persistent organic pollutants in ocean sediments from the North Pacific to the Arctic Ocean. Journal of 
Geophysical Research-Oceans 120, 2723-2735.

Ma, Y.X., Xie, Z.Y., Yang, H.Z., Moller, A., Halsall, C., Cai, M.H., Sturm, R., Ebinghaus, R., 2013. Deposition of polycyclic aromatic hydrocarbons in the North Pacific and the Arctic. Journal of Geophysical Research-Atmospheres 118, 5822-5829.

MacDonald, R.W., Barrie, L.A., Bidleman, T.F., Diamond, M.L., Gregor, D.J., Semkin, R.G., Strachan, W.M.J., Li, Y.F., Wania, F., Alaee, M., Alexeeva, L.B., Backus, S.M., Bailey, R., Bewers, J.M., Gobeil, C., Halsall, C.J., Harner, T., Hoff, J.T., Jantunen, L.M.M., Lockhart, W.L., Mackay, D., Muir, D.C.G., Pudykiewicz, J., Reimer, K.J., Smith, J.N., Stern, G.A., Schroeder, W.H., Wagemann, R., Yunker, M.B., 2000. Contaminants in the Canadian Arctic: 5 years of progress in understanding sources, occurrence and pathways. Science of the Total Environment 254, 93-234.

McGuire, A.D., Anderson, L.G., Christensen, T.R., Dallimore, S., Guo, L.D., Hayes, D.J., Heimann, M., Lorenson, T.D., Macdonald, R.W., Roulet, N., 2009. Sensitivity of the carbon cycle in the Arctic to climate change. Ecological Monographs 79, 523-555.

Nizzetto, L., Lohmann, R., Gioia, R., Jahnke, A., Temme, C., Dachs, J., Herckes, P., Di Guardo, A., Jones, K.C., 2008. PAHs in air and seawater along a North-South Atlantic transect: Trends, processes and possible sources. Environmental Science \& Technology 42, 1580-1585.

Okona-Mensah, K.B., Battershill, J., Boobis, A., Fielder, R., 2005. An approach to investigating the importance of high potency polycyclic aromatic hydrocarbons (PAHs) in the induction of lung cancer by air pollution. Food and Chemical Toxicology 43, 1103-1116.

Passow, U., Ziervogel, K., Asper, V., Diercks, A., 2012. Marine snow formation in the aftermath of the Deepwater Horizon oil spill in the Gulf of Mexico. Environmental Research Letters 7.

Schmidt, M.W.I., Noack, A.G., 2000. Black carbon in soils and sediments: Analysis, distribution, implications, and current challenges. Global Biogeochemical Cycles 14, 777-793.

Sericano, J.L., Brooks, J.M., Champ, M.A., Kennicutt, M.C., Makeyev, V.V., 2001. Trace contaminant concentrations in the Kara Sea and its adjacent rivers, Russia. Marine Pollution Bulletin 42, 1017-1030. Simcik, M.F., Eisenreich, S.J., Lioy, P.J., 1999. Source apportionment and source/sink relationships of PAHs in the coastal atmosphere of Chicago and Lake Michigan. Atmospheric Environment 33, 5071-5079.

Sofowote, U.M., Hung, H., Rastogi, A.K., Westgate, J.N., Deluca, P.F., Su, Y.S., McCarry, B.E., 2011. Assessing the long-range transport of $\mathrm{PAH}$ to a sub-Arctic site using positive matrix factorization and potential source contribution function. Atmospheric Environment 45, 967-976.

Tarr, M.A., Zito, P., Overton, E.B., Olson, G.M., Adhikari, P.L., Reddy, C.M., 2016. Weathering of Oil Spilled in the Marine Environment. Oceanography 29, 126-135.

Venkataraman, C., Lyons, J.M., Friedlander, S.K., 1994. SIRE DISTRIBUTIONS OF POLYCYCLIC AROMATIC-HYDROCARBONS AND ELEMENTAL CARBON .1. SAMPLING, MEASUREMENT METHODS, AND SOURCE CHARACTERIZATION. Environmental Science \& Technology 28, 555-562.

Wang, R., Tao, S., Wang, B., Yang, Y., Lang, C., Zhang, Y.X., Hu, J., Ma, J.M., Hung, H., 2010. Sources and Pathways of Polycyclic Aromatic Hydrocarbons Transported to Alert, the Canadian High Arctic. Environmental Science \& Technology 44, 1017-1022.

Witt, G., 1995. Polycyclic aromatic hydrocarbons in water and sediment of the Baltic Sea. Marine Pollution Bulletin 31, 237-248.

Yunker, M.B., Backus, S.M., Graf Pannatier, E., Jeffries, D.S., Macdonald, R.W., 2002a. Sources and significance of alkane and PAH hydrocarbons in Canadian arctic rivers. Estuarine Coastal and Shelf Science 55, 1-31. 
Yunker, M.B., Macdonald, R.W., 1995. Composition and Origins of Polycyclic Aromatic-Hydrocarbons in the Mackenzie River and on the Beaufort Sea Shelf. Arctic 48, 118-129.

496 Yunker, M.B., Macdonald, R.W., Snowdon, L.R., Fowler, B.R., 2011. Alkane and PAH biomarkers as

497 tracers of terrigenous organic carbon in Arctic Ocean sediments. Organic Geochemistry 42, 498 1109-1146.

499 Yunker, M.B., Macdonald, R.W., Vingarzan, R., Mitchell, R.H., Goyette, D., Sylvestre, S., 2002b. PAHs in 500 the Fraser River basin: a critical appraisal of PAH ratios as indicators of PAH source and composition. 501 Organic Geochemistry 33, 489-515.

502 Yunker, M.B., Snowdon, L.R., MacDonald, R.W., Smith, J.N., Fowler, M.G., Skibo, D.N., McLaughlin, F.A., 503 Danyushevskaya, A.I., Petrova, V.I., Ivanov, G.I., 1996. Polycyclic aromatic hydrocarbon composition 504 and potential sources for sediment samples from the Beaufort and Barents Seas. Environmental 505 Science \& Technology 30, 1310-1320.

506 Zhong, G.C., Xie, Z.Y., Cai, M.H., Moller, A., Sturm, R., Tang, J.H., Zhang, G., He, J.F., Ebinghaus, R., 2012. 507 Distribution and Air-Sea Exchange of Current-Use Pesticides (CUPs) from East Asia to the High Arctic 508 Ocean. Environmental Science \& Technology 46, 259-267.

509

510 


\section{Figure Captions}

512 Figure 1. Concentrations of PAHs $\left(\Sigma_{18}[\mathrm{PAHs}]\right)$ in the surface marine sediment along the sampling cruise.

Figure 2. Contributions of Nap, 1-MN \& 2-MN, other 2-3 ring PAH and 4-6 ring PAH to the $\mathrm{SPAH}$ in the five geographical regions.

Figure 3. Ratios of InP/(BghiP+InP) vs. Fluor/(Fluor+Py) in surface sediment along the cruise (a), in Bering Sea (b), Chukchi Sea shelf and slope of the

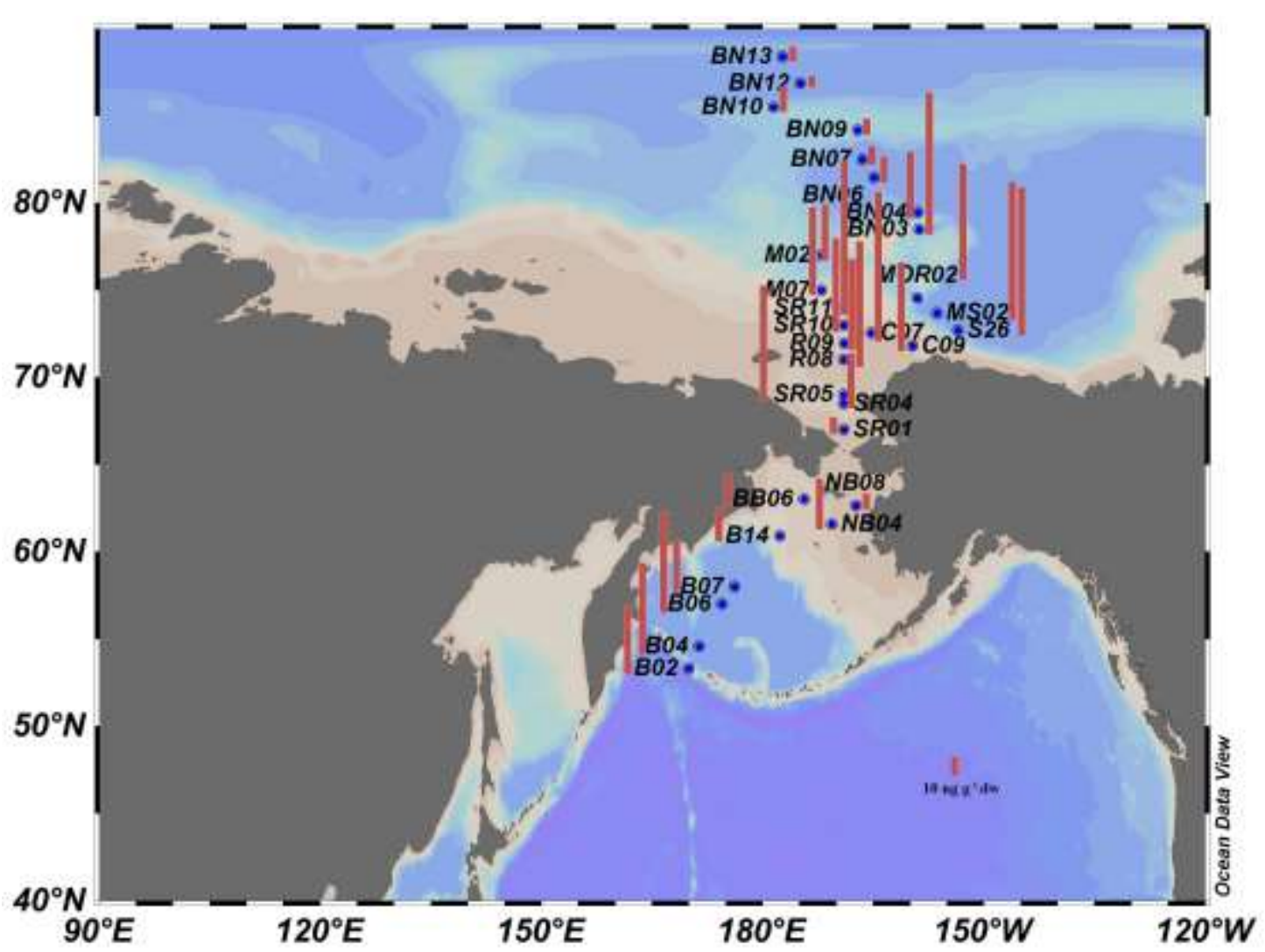

Figure 1. 


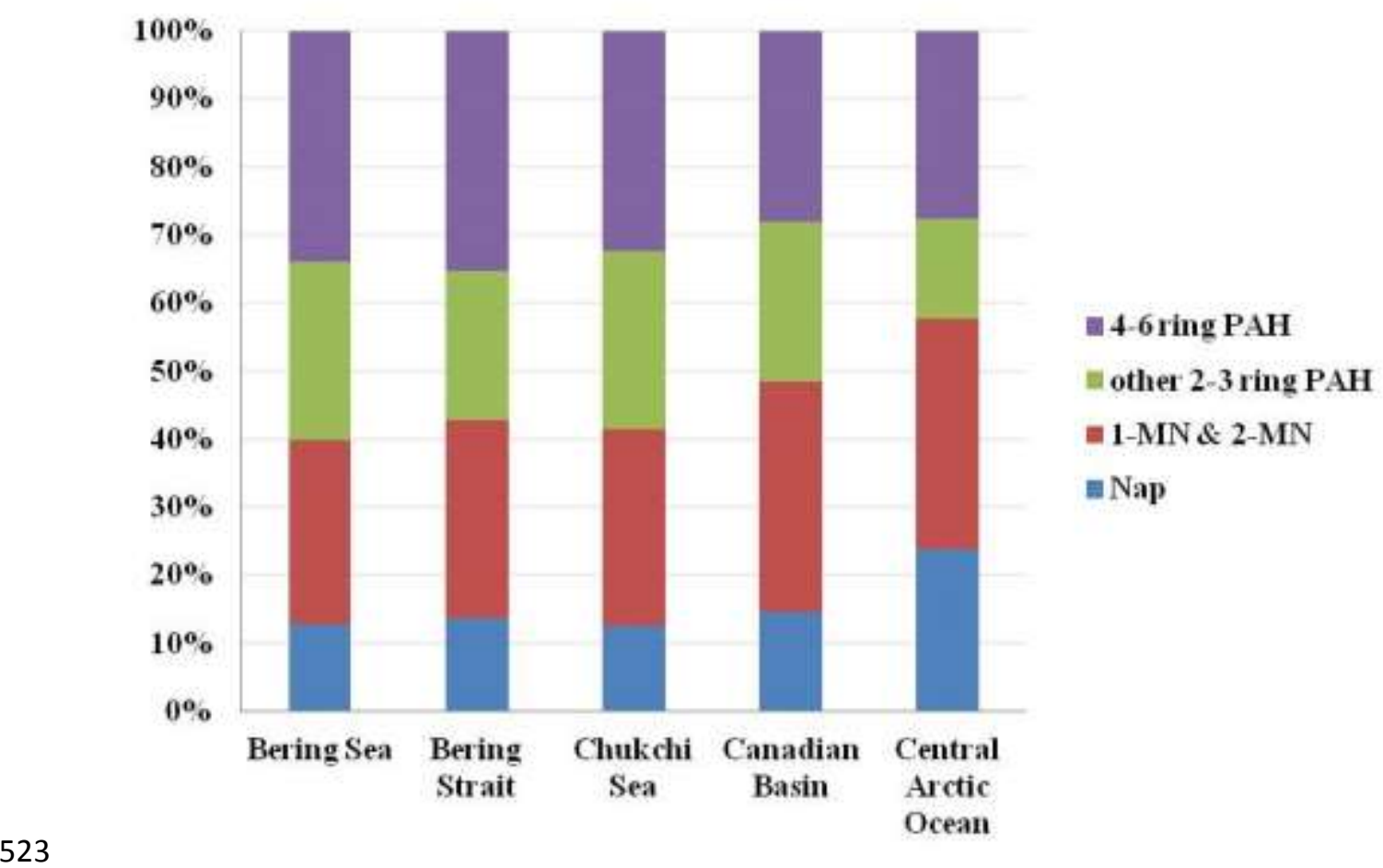

524

Figure 2.

525 

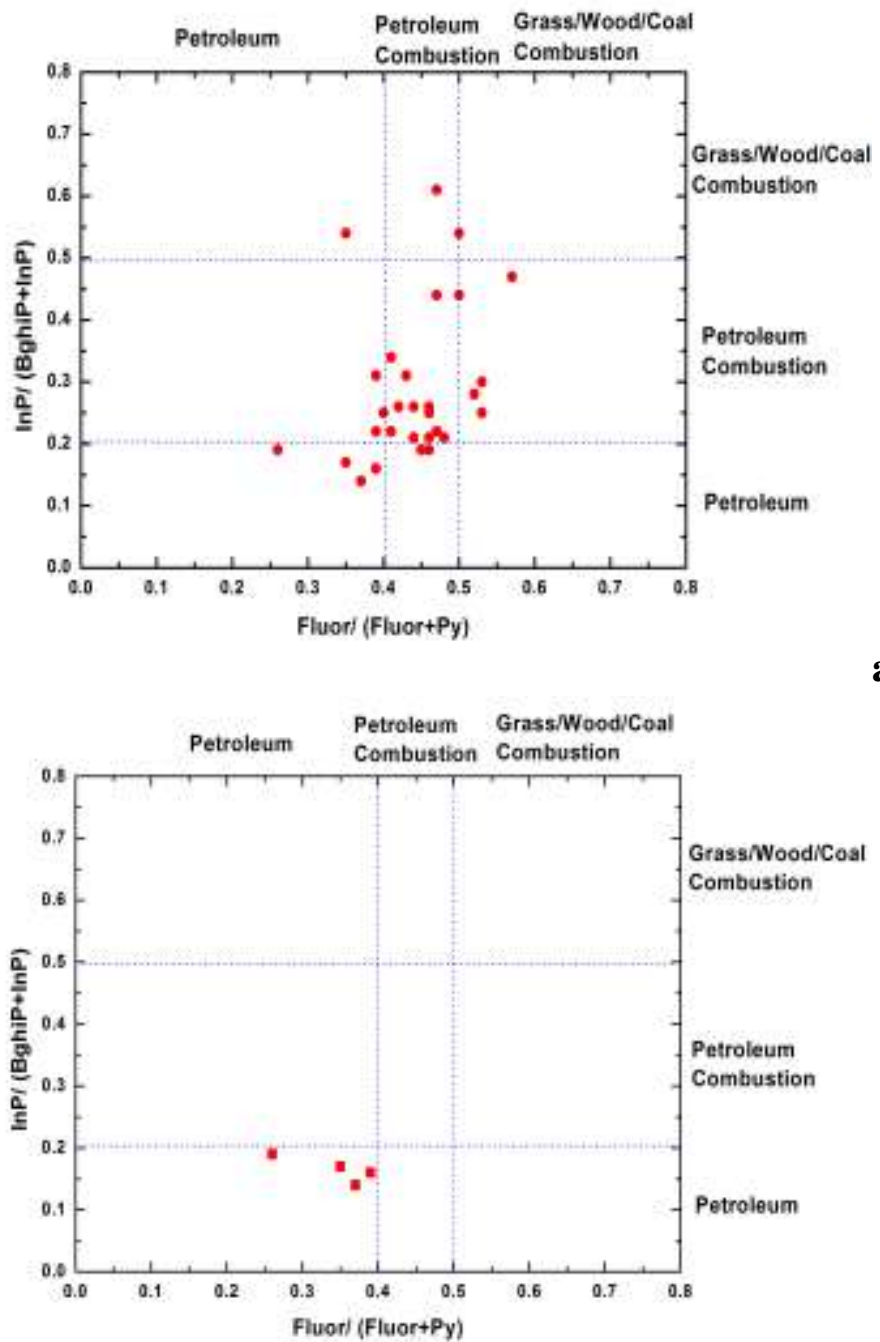

527

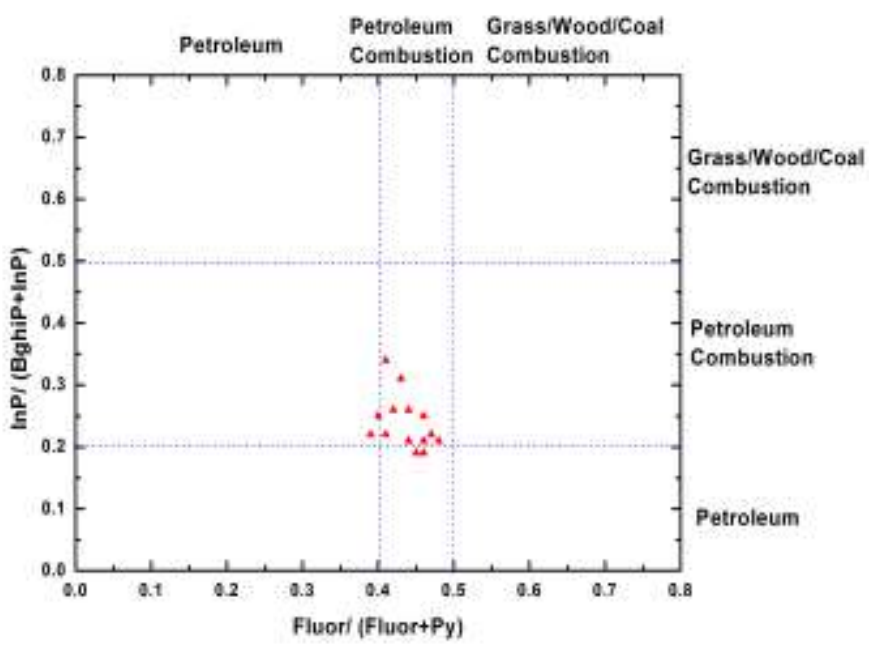




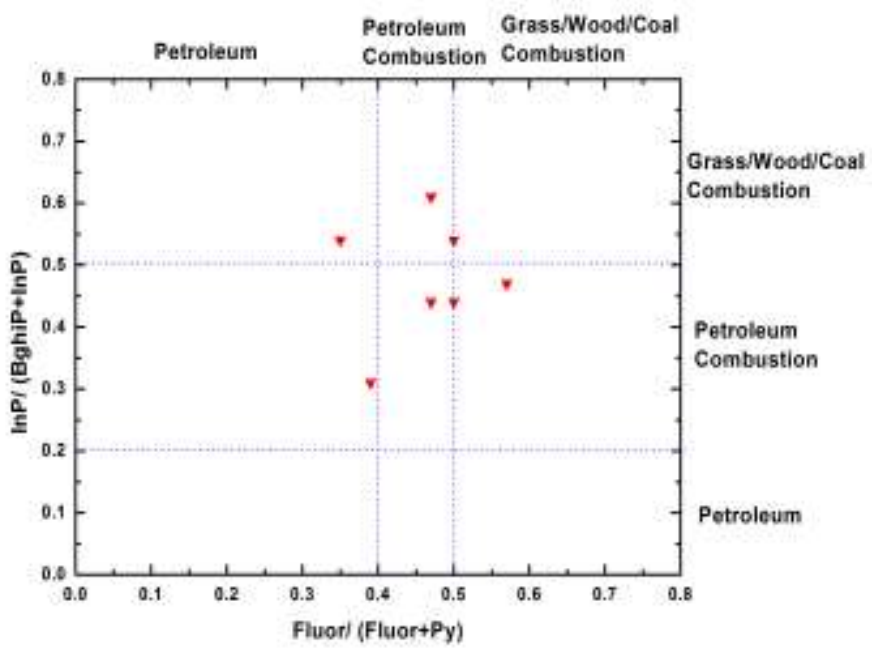

$530 \quad$ Figure 3. 
531 Table 1. Summary of $\Sigma_{18}$ PAHs concentrations ( $\mathrm{ng} \mathrm{g}^{-1}$ d.w.) in the surface sediment of 532 the Bering Sea, Bering Strait, Chukchi Sea, Canadian Basin and Central Arctic Ocean 533 for CHINARE 4 expedition.

\begin{tabular}{lllll}
\hline & Range & Median & Mean & S.D. \\
\hline Bering Sea & $26.2-51.2$ & 40.4 & 39.5 & 11.3 \\
Bering Strait & $8.5-25.8$ & 16.5 & 16.8 & 7.1 \\
Chukchi Sea & $8.8-78.3$ & 47.0 & 49.7 & 21.2 \\
Canadian Basin & $58.9-75.5$ & 70.5 & 68.3 & 8.5 \\
Central Arctic Ocean & $5.8-33.9$ & 9.7 & 13.1 & 9.6 \\
Entire Cruise & $5.8-78.3$ & 34.2 & 37.3 & 24.0 \\
\hline
\end{tabular}

535

536 Table 2. PAH variance explained and loadings of three significant factors by source 537 apportionment PCA analysis.

\begin{tabular}{lrrr}
\hline Donations & $\begin{array}{c}\text { Factor 1 } \\
\text { 32\% }\end{array}$ & $\begin{array}{c}\text { Factor 2 } \\
29 \%\end{array}$ & $\begin{array}{c}\text { Factor 3 } \\
27 \%\end{array}$ \\
\hline Fluor & .823 & .429 & .291 \\
Py & .807 & .397 & .359 \\
Flu & .805 & .495 & .042 \\
BaP & .784 & .163 & .502 \\
BaA & .703 & .251 & .270 \\
Chry & .665 & .544 & .477 \\
Acl & .654 & .650 & .357 \\
Ant & .430 & .145 & -.136 \\
Nap & .195 & .943 & .152 \\
twoMN & .330 & .912 & .204 \\
oneMN & .408 & .873 & .237 \\
Ace & .631 & .728 & .200 \\
Phe & .581 & .695 & .297 \\
IP & .121 & .081 & .951 \\
DBahA & .373 & .231 & .889 \\
BghiP & .405 & .181 & .867 \\
BbF & .402 & .354 & .820 \\
BkF & -.216 & .168 & .736 \\
\hline
\end{tabular}

